\title{
Tetrabenazine: the first approved drug for the treatment of chorea in US patients with Huntington disease
}

This article was published in the following Dove Press journal:

Neuropsychiatric Disease and Treatment

24 September 2010

Number of times this article has been viewed

\section{Samuel Frank}

Boston University School of Medicine, Boston, Massachusetts, USA
Correspondence: Samuel Frank Boston University School of Medicine, 72 East Concord St, C329, Boston, MA 02118, USA

Tel + I 6176388647

Fax +16176385354

Email samfrank@bu.edu
Abstract: Huntington disease (HD) is a dominantly inherited progressive neurological disease characterized by chorea, an involuntary brief movement that tends to flow between body regions. HD is typically diagnosed based on clinical findings in the setting of a family history and may be confirmed with genetic testing. Predictive testing is available to those at risk, but only experienced clinicians should perform the counseling and testing. Multiple areas of the brain degenerate mainly involving the neurotransmitters dopamine, glutamate, and $\gamma$-aminobutyric acid. Although pharmacotherapies theoretically target these neurotransmitters, few well-conducted trials for symptomatic or neuroprotective interventions yielded positive results. Tetrabenazine (TBZ) is a dopamine-depleting agent that may be one of the more effective agents for reducing chorea, although it has a risk of potentially serious adverse effects. Some newer antipsychotic agents, such as olanzapine and aripiprazole, may have adequate efficacy with a more favorable adverse-effect profile than older antipsychotic agents for treating chorea and psychosis. This review will address the epidemiology and diagnosis of HD as background for understanding potential pharmacological treatment options. Because TBZ is the only US Food and Drug Administration-approved medication in the United States for HD, the focus of this review will be on its pharmacology, efficacy, safety, and practical uses. There are no current treatments to change the course of HD, but education and symptomatic therapies can be effective tools for clinicians to use with patients and families affected by HD.

Keywords: dopamine-depleting agent, neuroleptics, tetrabenazine

\section{Introduction}

Huntington disease (HD) is a hereditary, progressive neurodegenerative disease clinically characterized by abnormal involuntary movements, behavioral disturbance, cognitive dysfunction, and psychiatric disease. The disease is caused by a CAG (glutamine) trinucleotide expansion in exon 1 of the huntingtin $(h t t)$ gene at the location 4 p16.9. ${ }^{1}$ The function of htt is not known, but it may be involved in internal cell signaling, maintenance of cyclic adenosine monophosphate response element binding protein, and preventing neuronal toxicity. ${ }^{2}$ Early evidences suggest that the binding of the Ras homologue enriched in striatum (Rhes) protein to htt may be necessary to cause cellular toxicity. ${ }^{3}$ However, why the protein causes cellular toxicity in adulthood is not well understood. Recent evidence suggests that the interaction of the group 1 metabotropic glutamate receptors and $h t t$ protein may be at the root of delayed onset. ${ }^{4}$

Although there is no established treatment to delay the onset or forestall the progression of HD, symptomatic treatment of chorea may be beneficial in some individuals, as it may have a favorable effect on motor function, quality of life, and safety. ${ }^{5-7}$ 
Pathologically, HD is associated with diffuse loss of neurons, particularly involving the cortex and the striatum. Medium spiny neurons in the striatum that contain $\gamma$-aminobutyric acid (GABA) and enkephalin are impacted early in the disease, and are the primary neurons targeted in HD. These neurons typically project into the lateral globus pallidus. Then, there is progression to the remainder of the basal ganglia with subsequent dissemination, including cortex and substantia nigra. There are intranuclear and cytoplasmic inclusions of the $h t t$ aggregate. Huntingtin is cross-linked with other soluble $h t t$ to form the inclusion bodies in neurons. It is not known if the accumulation of $h t t$ conglomerate results in cell death, or if the soluble form of the protein is the toxic form. ${ }^{8}$ Dopamine, glutamate, and GABA are thought to be the most involved neurotransmitters in HD and are targeted for treatment (Table 1). ${ }^{10-23}$

There are multiple theories on the pathogenesis of HD. It is likely that more than 1 process may be occurring at once, but there is evidence to support multiple individual mechanisms, including toxic neuronal aggregates, transcriptional dysregulation, excitotoxicity, mitochondrial dysfunction with altered energy metabolism, and changes in axonal transport and synaptic dysfunction (Table 2)..$^{24-30,31}$

\section{Epidemiology}

Most European populations show a prevalence rate of 4-8 cases per 100,000, and HD may be frequently seen in India and parts of Central Asia. ${ }^{32}$ More recent studies in other European nations have confirmed this prevalence rate..$^{33,34}$ HD is notably rare in Finland and Japan, but data for Eastern Asia and Africa are inadequate. Outside of Venezuela, there are little epidemiological studies of HD in Hispanic populations. A recent study found a slightly higher prevalence rate than expected and higher proportion of juvenile cases in Mexico. ${ }^{35}$ There are also well-known large populations of

Table I Neurotransmitters involved in the pathogenesis of Huntington disease

\begin{tabular}{lll}
\hline Receptor & Location & Stage of disease \\
\hline Adenosine & Striatum, GPe & Preclinical to advanced \\
A2A & & \\
Cannabinoid & Striatum, GPe & Preclinical to advanced \\
Dopamine $D_{1}$ & Striatum, substantia nigra & Clinical diagnosis to advanced \\
Dopamine $D_{2}$ & Caudate, putamen & Prodromal \\
Dynorphin & Striatum & Emergence of dystonia \\
Enkephalin & Striatum & Emergence of chorea \\
GABA & Striatum & Advanced \\
Glutamate & Cortical & Preclinical to advanced \\
Substance P & Striatum & Emergence of dystonia \\
\hline
\end{tabular}

Abbreviations: GPe, globus pallidus externa; GABA, $\gamma$-aminobutyric acid.
Table 2 Potential pathways for pathogenesis of Huntington disease

\section{Neuronal aggregates}

Neuronal intracytoplasmic and intranuclear inclusions containing mutant huntingtin, truncated $\mathrm{N}$-terminal mutant and wild-type fragment, and chaperones and components of the proteolytic pathway are characteristic of HD neuropathology

Accumulation of mutant protein aggregates may be a result of impairment of the ubiquitin-proteosome pathway

Autophagic mechanisms are implicated in the clearance of protein aggregates

\section{Transcriptional dysregulation}

Aberrant nuclear localization of mutant toxic huntingtin fragments and their association with transcription factors

Dysregulation related to entrapment of transcriptional factors in protein aggregates

\section{Excitotoxicity}

Excitotoxic neuron death in HD could result from a combination of increased glutamate and glutamate agonist release from cortical afferents Mitochondrial dysfunction and altered energy metabolism Selective inhibitors of complex II of the mitochondrial electron transport chain, 3-NP and malonate, cause selective striatal neuronal loss similar to that seen in patients with HD

Multitude of bioenergetic defects have been reported in patients with HD

Changes in axonal transport and synaptic dysfunction

Normal huntingtin plays a role in axonal trafficking

Disruption of axonal transport contributes to pathologic process in HD

Abbreviations: HD, Huntington disease; NP, nitropropionic acid.

patients with HD in Scotland and the Lake Maracaibo region of Venezuela. ${ }^{36,37}$ The disorder may be underestimated in the Black American population. There have been no widespread epidemiological studies of HD in the United States since the wide availability of genetic testing, but it is estimated that approximately 25,000-30,000 individuals have manifest HD and a further 150,000-250,000 individuals are at risk for HD. ${ }^{38}$

Men and women are affected equally and typically become symptomatic in the third and fourth decades. The symptoms of HD can start at any age ranging from 1 to 90 years. Approximately 5\%-10\% of cases are classified as juvenile onset, with symptoms starting before the age of 20 years. The vast majority of juvenile cases are inherited paternally, and instead of chorea, patients may exhibit more parkinsonian signs of bradykinesia, dystonia, tremors, and cognitive deficit. ${ }^{39}$ When patients exhibit more hypokinetic features (bradykinesia and dystonia) vs hyperkinetic features (chorea), they are said to have the Westphal variant of HD.

\section{Diagnosis}

HD is diagnosed based on the presence of typical motor findings as measured by the Unified Huntington's Disease 
Rating Scale in the setting of a family history of the disease. There may be other manifestations of HD at the time of presentation or prior to diagnosis based on behavioral and cognitive symptoms. A DNA test showing abnormal CAG expansion in the $h t t$ gene can be used to confirm the diagnosis in symptomatic individuals. With proper genetic counseling and at the patient's request, DNA analysis can be performed in individuals at risk for developing HD under the care of experienced clinicians. There are many reasons why patients request presymptomatic testing, including financial planning, family planning, insurance decisions, and the need to know. Some people at risk for HD are reluctant to undergo testing and are brought into the clinic by future spouse, family, or others who believe testing should be performed. Under these circumstances or if the at-risk individual is likely to harm themselves or others based on the outcome of the test, genetic testing should be reconsidered.

There are ongoing studies to examine individuals who are gene positive but not yet symptomatic by motor criteria (TRACK-HD, Neurobiological Predictors of Huntington's Disease Trial [PREDICT-HD], Prospective Huntington at Risk Observational Study [PHAROS]). ${ }^{40-43}$ There is also a study currently enrolling subjects with HD and their affected and unaffected family members to further understand biomarkers of disease and signs of onset (Cooperative Huntington's Observational Research Trial [COHORT]). ${ }^{44}$ The focus of the COHORT study is not neuroimaging and anatomical measures but rather clinical measures and biological samples.

Subtle motor abnormalities have been associated with a smaller striatal volume and higher probability of disease diagnosis. ${ }^{40}$ Lower scores on the Hopkins Verbal Learning Test-Revised were associated with closer proximity to diagnosis and smaller striatal volumes. ${ }^{44}$ Subjects with an expanded repeat and preclinical diagnosis of HD also had less accurate recognition of negative emotions. ${ }^{45}$ In addition, motor exam score, striatal volume, speeded finger tapping, self-timed finger tapping, word-list learning, and odor identifications in subjects in the PREDICT-HD study were all associated with the predicted time to diagnosis. ${ }^{46}$ Expansion-positive individuals reported more psychiatric symptoms (depression, anxiety, obsessivecompulsiveness) than expansion-negative individuals. ${ }^{47}$ The TRACK-HD study has confirmed some and expanded upon findings in PREDICT-HD in that presymptomatic subjects had significant changes in whole-brain volume, regional grey and white matter differences, impairment in a range of motor tasks, oculomotor findings, and cognitive and neuropsychiatric dysfunctions. The various motor and nonmotor measures on the neurological examination used to diagnose and track HD are included in the Unified Huntington's Disease Rating Scale. ${ }^{48}$ The scale is divided into 6 sections: motor, cognitive, behavioral, and 3 functional scales (total functional capacity, functional checklist, and the independence scale).

Based on the guidelines published by the American College of Genetics, patients with 40 or more repeats have $100 \%$ penetrance..$^{49}$ In other words, if patients have 40 or more copies of the gene, they will inevitably express the disease clinically. In patients with a CAG repeat length in the range of 36-39, there is reduced penetrance with increased likelihood of expression occurring with longer length of repeats and with longer lifespan of the patient. Although there are case reports of patients who manifest $\mathrm{HD}$ in this range, patients with fewer than 36 repeats will generally not develop clinical disease. ${ }^{50,51}$ Patients with an allele repeat size of 27-35 have demonstrated meiotic instability, particularly in sperm, indicating that the following generation is at higher risk of inheriting an expanded number of repeats, increasing the risk of clinical disease. The length of repeat size correlates generally with the age of onset, but not necessarily with the severity or duration of disease. ${ }^{52}$

The course of the disease is typically 15-20 years, with dementia, mutism, dystonia, and bradykinesia predominating in end-stages. Patients with more dystonia and swallowing issues may experience accelerated complications and, therefore, shorter lifespan. Chorea may become a safety issue with larger amplitude movements causing injury or poor positioning. Frequent movements may result in skin injuries, infections, or even fractures and head trauma. Cause of death is typically related to complications of immobility, such as skin breakdown, pneumonia, cardiac disease, or infection. However, $25 \%$ of patients attempt suicide, which is a cause of death in $8 \%-9 \%$ of patients. ${ }^{53}$

Behavioral dyscontrol can be a severely disabling symptom of HD causing distress to the patient, family, and caregivers. Environmental approaches and cognitive interventions are the mainstay of treatments, but pharmacological agents can augment addressing disruptive behaviors. Depression, anxiety, aggressive, impulsive, and obsessive-compulsive behaviors are also frequently treated pharmacologically and require behavioral intervention, but caution should be used to avoid oversedation and apathy, already common in patients with HD. Although not well studied, cognitive approaches to treat behavior may be more effective than pharmacotherapy for some aspects of the disease. ${ }^{54}$ 


\section{Pharmacological treatment options}

Many agents and surgical procedures have been evaluated in HD for their efficacy on suppressing chorea, including dopamine-depleting agents, dopamine antagonists, benzodiazepines, glutamate antagonists, acetylcholinesterase inhibitors, dopamine agonists, antiseizure medications, cannabinoids, lithium, deep brain stimulation, and fetal cell transplantation. ${ }^{55-58}$ Pharmacological interventions typically address the hyperkinetic movement disorders that may be associated with HD, such as chorea, dystonia, ballism, myoclonus, and tics. With regards to choose the agent, providers need to consider if there will be a positive or negative impact of the agent on psychiatric issues associated with $\mathrm{HD}$, such as irritability, depression, anxiety, mania, apathy, obsessivecompulsive disorder, or cognitive decline associated with HD. Adjunctive therapies, alternative and complementary therapies, behavioral plans, and cognitive interventions also may play a role in addressing the symptoms of HD and need to be considered when choosing medications.

Several excellent reviews have summarized the symptomatic treatment of HD. ${ }^{55-67}$ Overall, there is not enough evidence available to guide long-term symptomatic treatment in $\mathrm{HD}$, and double-blind and long-term studies assessing various treatment strategies in $\mathrm{HD}$ are needed.${ }^{61} \mathrm{~A}$ Cochrane review of studies for the symptomatic treatment of HD examined 22 trials that involved 1,254 different participants. ${ }^{62}$ Nine trials had a crossover design and 13 were conducted in parallel. The studies examined were of relatively short duration, ranging from 2 to 80 weeks. The number of trials examining various pharmacological interventions included antidopaminergic drugs $(n=5)$, glutamate receptor antagonists $(n=5)$, and energy metabolites $(n=5)$. Based on available evidence, the authors of the Cochrane review concluded that only tetrabenazine (TBZ) showed clear efficacy for the control of chorea, but "no statement can be made regarding the best medical practice for the control of motor and non-motor symptoms in HD".

\section{Tetrabenazine}

TBZ is the only US Food and Drug Administration (FDA)approved drug for HD, indicated for the treatment of chorea associated with HD. In addition to the United States and Canada, TBZ is marketed in Australia, Denmark, France, Germany, Ireland, Israel, Italy, New Zealand, Portugal, Spain, Switzerland, and United Kingdom. An excellent review of the chemistry, pharmacodynamics, pharmacokinetics, and mechanism of action is available in a previous issue of this journal. ${ }^{68}$ By reversibly inhibiting the central vesicular monoamine transporter type 2 (VMAT2), TBZ more selectively depletes dopamine than norepinephrine. ${ }^{69,70}$ The highest binding density for TBZ is in the caudate nucleus, putamen, and nucleus accumbens, areas known to bear the brunt of pathology in HD. ${ }^{71,72}$ VMAT2 binding and monoamine depletion by TBZ are reversible, last hours, and are not modified by long-term treatment. ${ }^{73,74}$ These features of the drug differentiate it from the other dopamine-depleting agent, reserpine. Reserpine binds to both VMAT1 and VMAT2. While VMAT2 is located solely in the central nervous system, VMAT1 is localized to the peripheral nervous system, accounting for some of the peripheral adverse effects, such as orthostatic hypotension and diarrhea. In contrast to TBZ, reserpine binds irreversibly to VMAT1 and VMAT2, making the duration of action considerably longer (hours vs days). In addition to TBZ, the 2 active metabolites, $\alpha$ - and $\beta$-dihydrotetrabenazine, have longer half-lives and are more highly bound to proteins than the parent compound. ${ }^{75-77}$

The efficacy of TBZ as an antichoreic drug was convincingly demonstrated in a double-blind, placebo-controlled trial conducted by the Huntington Study Group (HSG) ${ }^{78}$ Subjects were randomized to receive either TBZ $(\mathrm{n}=54)$ or placebo $(\mathrm{n}=30)$. TBZ was titrated weekly in $12.5 \mathrm{mg}$ increments to a maximum of $100 \mathrm{mg} / \mathrm{d}$ or to the development of intolerable adverse effects. The primary efficacy outcome was the change from baseline in the total maximal chorea score of the Unified Huntington's Disease Rating Scale. ${ }^{48}$ On this scale, chorea is graded from 0 to 4 (with 0 representing no chorea) for 7 body regions for a range in total scores from 0 to 28 . Compared with baseline, TBZ treatment resulted in a reduction of 5.0 units in chorea compared with a reduction of 1.5 units in the placebo group. About $50 \%$ of TBZ-treated subjects had a 6-point or greater improvement compared with $7 \%$ of placebo recipients. There is also evidence to suggest continuous long-term efficacy and tolerability of TBZ in patients with HD. ${ }^{79-82}$

In the same study, the adverse events that occurred significantly more frequently in the TBZ group included drowsiness or somnolence, insomnia, depressed mood, agitation, akathisia, and hyperkinesia. However, by the conclusion of the maintenance phase, when subjects were presumably on optimal dosage, there were no significant differences between TBZ and placebo. Among subjects completing the study, the most common adverse event at the end of TBZ exposure was fatigue, reported by 7 subjects on TBZ (14.3\%) and 2 on placebo $(6.9 \%)$. There was 1 suicide in the double-blind study in a subject taking TBZ. Depression is common in HD and can be exacerbated by TBZ. However, attempted 
or completed suicides in HD do not necessarily correlate with severity of depression and may be related to associated impulsiveness, obsessive-compulsive behavior, and a variety of socioeconomic factors. Nevertheless, all patients taking TBZ need to be monitored for signs of depression and suicidal ideation. Cognition in the TBZ group, as assessed by the Unified Huntington's Disease Rating Scale, did not differ from that in the placebo group statistically, although both groups declined as expected over the course of the study. There were no HD-related quality-of-life measures included in the published TBZ studies.

The same group of study participants was given the opportunity to participate in an open-label extension study. ${ }^{82}$ Seventy-five subjects were elected to participate initially, and at the end of the 3 phases of the extension study, 45 subjects had completed 80 additional weeks of treatment with TBZ. In the extension study, no new adverse effects were reported, and the drug was well tolerated, despite the attrition rate in the study (mostly for logistical reasons). There are a number of older open-label studies, primarily out of the Baylor College of Medicine database. ${ }^{80}$ The side effects and doses reported were fairly consistent with the double-blind study with the exception of insomnia. Chronic doses of the Baylor group were comparable with that in the long-term HSG study of 62.5-mg total daily dose.

The safety of TBZ was evaluated in these studies, and in an additional study, the safety of sudden withdrawal after long-term use was assessed. The side effects are consistent among studies, and once the drug is titrated slowly to effect, the drug is well tolerated. Potential side effects include akathisia, depression, dizziness, fatigue, or parkinsonism (Table 3). During titration, patients may experience insomnia,

Table 3 Treatment-emergent side effects to monitor for when using tetrabenazine

During titration
Insomnia
Somnolence
Gastrointestinal distress
During chronic therapy
Sedation
Depressed mood (and suicidality)
Anxiety
Insomnia
Akathisia
Fatigue
Agitation
Falls
Dysphagia
Dysarthria

somnolence, or gastrointestinal distress. If at any time side effects do occur, the dose can be lowered to the previously well-tolerated dose. Since the half-life is short, side effects tend to wane quickly. Withdrawal of TBZ results in a recurrence of chorea, not worse than before starting the drug. ${ }^{83}$ There are no particular characteristics that may predispose patients to experience 1 or more side effects, but patients with a history of depression should be more closely monitored for changes in mood or impulsivity. Although it is listed in the product information sheet, TBZ does not cause and in fact may be an excellent treatment for tardive dyskinesia.

\section{Other antichorea medications}

Other medications that are commonly considered when treating chorea include dopamine antagonists, benzodiazepines, and glutamate antagonists. Dopamine antagonists (neuroleptics) are perhaps the most commonly considered agents in the management of chorea and psychosis in patients with HD, but few double-blind, placebo-controlled studies evaluating the efficacy and safety of these agents have been published. ${ }^{84-86}$ None of the typical neuroleptics have been found to be effective in reducing chorea in placebo-controlled trials. However, in a study of haloperidol in 10 subjects, oral doses of $1.5-10 \mathrm{mg} / \mathrm{d}$ corresponded with at least a $30 \%$ reduction in chorea compared with baseline. ${ }^{87}$ The quantity and quality of these efficacy data need to be taken into account when considering the risks of using typical neuroleptics, particularly tardive dyskinesia. Apathy and akathisia, other potential adverse effects of the dopamine receptor blockers, can be particularly problematic in patients with HD, as they may not have the insight to recognize these problems or may wrongly attribute the symptoms to HD.

Owing to their presumed better tolerability, atypical antipsychotics have recently been evaluated in HD. Olanzapine has been used in small open-label studies to treat the motor symptoms of HD. ${ }^{88-92}$ The range of effect on chorea has been $0 \%-66 \%$ reduction. There are no clinical trials of risperidone for $\mathrm{HD}$, but a few reports suggest a positive effect on the disease with a tolerable adverse-effect profile. ${ }^{93-97}$ Quetiapine has been tried in multiple, small, uncontrolled, nonrandomized trials for HD with some success on both motor and psychiatric symptoms of HD. ${ }^{97-99}$ Clozapine was studied in patients with HD up to a dose of $150 \mathrm{mg} / \mathrm{d}$ for up to 31 days, but many adverse events, such as drowsiness, fatigue, anticholinergic symptoms, and walking difficulties, occurred without beneficial effects. ${ }^{100}$ The newer atypical agent with multiple mechanisms of action, aripiprazole, has been found to be beneficial in a few small trials with a reduction in chorea equivalent to that with TBZ. ${ }^{101-103}$ 
Although aripiprazole may have fewer adverse effects on mood than TBZ, it is associated with tardive dyskinesia, similar to other typical and atypical neuroleptics.

The N-methyl D-aspartate-antagonist amantadine has been shown in controlled trials to significantly reduce chorea in patients with HD. ${ }^{104}$ Doses in the range of $400 \mathrm{mg} / \mathrm{d}$ or higher may be required for symptomatic benefit, but even in doses used to treat influenza, amantadine may increase irritability and aggressiveness. ${ }^{105}$ Because riluzole retards striatal glutamate release and the pathological consequences in neurotoxic animal models of HD, multiple large trials have been conducted to determine if there is a possible neuroprotective effect. Riluzole was found to reduce chorea at a dose of $200 \mathrm{mg} / \mathrm{d}$, but not $100 \mathrm{mg} / \mathrm{d} .{ }^{106,107}$ Benzodiazepines are also frequently used clinically in patients with HD to treat anxiety and chorea, and there is limited evidence to suggest that higher doses of clonazepam (up to $5.5 \mathrm{mg} / \mathrm{d}$ ) may be needed to suppress chorea. ${ }^{108}$ At this dose, sedation becomes a potential adverse effect. In a few short-term studies (hours), there is evidence that dopamine agonists may reduce the motor signs of HD. ${ }^{109-111}$ Although the pharmacological rationale for using dopamine agonists in the treatment of chorea is not clear, presumably they act by activating the presynaptic dopamine receptors leading to decreased dopamine turnover. More likely, however, is that the observed symptomatic effects are related to nonspecific or sedating effects.

For patients with the akinetic form of HD (Westphal variant), antiparkinsonian medications, such as levodopa, dopamine agonists, and amantadine, may be beneficial. ${ }^{112-115}$ Botulinum toxin injections can also be considered for focal dystonia associated with HD.

\section{Practical uses of TBZ}

TBZ is formulated in 12.5- and 25-mg tablets. The medication is not available at local pharmacies but must be ordered through a central distribution center. Prescription information can be found through the company's Web site, including prescribing information and obtaining the prescription form. ${ }^{116}$ Clinicians should note on the form that patients (or their guardian) must sign the release of information for the pharmacy to be able to communicate with the patient's insurance company.

TBZ should be started at $12.5 \mathrm{mg} / \mathrm{d}$, and every week, the dose should be increased by $12.5 \mathrm{mg} / \mathrm{d}$, distributing the drug in 3-times daily dosing. Once patients reach twice-daily dose of $12.5 \mathrm{mg}$ and daily dose of $25 \mathrm{mg}$ (total daily dose of $50 \mathrm{mg}$ ), as per the prescribing information, "before patients are given a daily dose of greater than $50 \mathrm{mg}$, they should be tested for the CYP2D6 gene to determine whether they are poor, extensive, or intermediate metabolizers". This test can be costly (up to $\$ 3,000$ ) and may or may not be covered by insurance. In addition, the drug is titrated to clinical effect, and the genotyping has no impact on the clinical assessment of the patient on the drug. Ultimately, it is up to the discretion of the provider with the patient to determine if this test should be performed.

The goal of the effect of TBZ is to reduce chorea to a point that is acceptable to the patient. The goal should not be to eliminate chorea completely or to reduce chorea to a level that is acceptable to the caregiver or even physician treating the patient. The most common scenario is the titration of the drug to a side effect and then reducing the daily dose to a tolerated dose. Because HD is a progressive disease that changes over time, the dose of TBZ needs to be reassessed frequently (every 2-3 months). TBZ interacts with other CYP2D6 inhibitors, such as paroxetine. There is no evidence if TBZ can be used safely or effectively with neuroleptics or other commonly used medications for chorea.

\section{Conclusion}

Until clear neuroprotective strategies are found, clinicians can address the symptoms of patients with this devastating disease. The most and best evidence for treating troublesome chorea leads toward TBZ, but other abnormal involuntary movements, cognition, affective disorders, and behavioral dyscontrol all need to be considered when choosing therapies for patients. Further studies to determine interactions and combination therapy of TBZ need to be completed, as most patients need multiple medications to adequately address symptoms. Other issues related to HD also need to be studied more closely when treating patient with TBZ. Although there is one FDA-approved option at this time and other medications hopefully soon to be available, there are not enough effective, safe interventions that can be offered to our patients and their families with this invariably fatal disease.

\section{Disclosure}

The author reports no conflicts of interest in this work.

\section{References}

1. The Huntington's Disease Collaborative Research Group. A novel gene containing a trinucleotide repeat that is expanded and unstable on Huntington's disease chromosomes. Cell. 1993;72(6):971-983.

2. Nucifora FC Jr, Sasaki M, Peters MF, et al. Interference by huntingtin and atrophin-1 with cbp-mediated transcription leading to cellular toxicity. Science. 2001;291(5512):2423-2428.

3. Subramaniam S, Sixt KM, Barrow R, Snyder SH. Rhes, a striatal specific protein, mediates mutant-huntingtin cytotoxicity. Science. 2009; 324(5932):1327-1330. 
4. Ribeiro FM, Paquet M, Ferreira LT, et al. Metabotropic glutamate receptor-mediated cell signaling pathways are altered in a mouse model of Huntington's disease. J Neurosci. 2010;30(1):316-324.

5. Andrich J, Saft C, Ostholt N, Müller T. Complex movement behavior and progression of Huntington's disease. Neurosci Lett. 2007;416(3): 272-274.

6. Frank S, Marshall F, Plumb S, et al. Functional decline due to chorea in Huntington's disease. Neurology. 2004;62 Suppl 5:A204.

7. Verhagen ML, Morris MJ, Farmer C, et al. Huntington's disease: a randomized, controlled trial using the NMDA-antagonist amantadine. Neurology. 2002;59(5):694-699.

8. Bates G. Huntingtin aggregation and toxicity in Huntington's disease. Lancet. 2003;361(9369):1642-1644.

9. Arrasate M, Mitra S, Schweitzer ES, Segal MR, Finkbeiner S. Inclusion body formation reduces levels of mutant huntingtin and the risk of neuronal death. Nature. 2004;431(7010):805-810.

10. Glass M, Dragunow M, Faull RL. The pattern of neurodegeneration in Huntington's disease: a comparative study of cannabinoid, dopamine, adenosine and $\operatorname{GABA}(\mathrm{A})$ receptor alterations in the human basal ganglia in Huntington's disease. Neuroscience. 2000;97(3): 505-519.

11. Albin RL, Reiner A, Anderson KD, et al. Preferential loss of striatoexternal pallidal projection neurons in presymptomatic Huntington's disease. Ann Neurol. 1992;31(4):425-430.

12. Reiner A, Albin RL, Anderson KD, D'Amato CJ, Penney JB, Young AB. Differential loss of striatal projection neurons in Huntington disease. Proc Natl Acad Sci US A. 1988;85(15):5733-5737.

13. Mitchell IJ, Cooper AJ, Griffiths MR. The selective vulnerability of striatopallidal neurons. Prog Neurobiol. 1999;59(6):691-719.

14. Antonini A, Leenders KL, Spiegel R, et al. Striatal glucose metabolism and dopamine D2 receptor binding in asymptomatic gene carriers and patients with Huntington's disease. Brain. 1996;119(Pt 6): 2085-2095.

15. Augood SJ, Faull RL, Emson PC. Dopamine D1 and D2 receptor gene expression in the striatum in Huntington's disease. Ann Neurol. 1997;42(2):215-221.

16. Feigin A, Tang C, MaY, et al. Thalamic metabolism and symptom onset in preclinical Huntington's disease. Brain. 2007;130(Pt 11): 2858-2867.

17. Andrews TC, Weeks RA, Turjanski N, et al. Huntington's disease progression. PET and clinical observations. Brain. 1999;122(Pt 12): 2353-2363.

18. Weeks RA, Piccini P, Harding AE, et al. Striatal D1 and D2 dopamine receptor loss in asymptomatic mutation carriers of Huntington's disease. Ann Neurol. 1996;40(1):49-54.

19. Cha JH, Kosinski CM, Kerner JA, et al. Altered brain neurotransmitter receptors in transgenic mice expressing a portion of an abnormal human huntington disease gene. Proc Natl Acad Sci USA. 1998;95(11): 6480-6485.

20. Perry TL, Hansen S, Kloster M. Huntington's chorea. Deficiency of gammaaminobutyric acid in brain. N Engl J Med. 1973;288(7): 337-342.

21. Paulsen JS. Functional imaging in Huntington's disease. Exp Neurol. 2009;216(2):272-277.

22. Gourfinkel-An I, Parain K, Hartmann A, et al. Changes in GAD67 mRNA expression evidenced by in situ hybridization in the brain of R6/2 transgenic mice. J Neurochem. 2003;86(6):1369-1378.

23. Nicniocaill B, Haraldsson B, Hansson O, et al. Altered striatal amino acid neurotransmitter release monitored using microdialysis in R6/1 Huntington transgenic mice. Eur J Neurosci. 2001;13(1): 206-210.

24. Li SH, Li XJ. Huntingtin-protein interactions and the pathogenesis of Huntington's disease. Trends Genet. 2004;20(3):146-154.

25. Bence NF, Sampat RM, Kopito RR. Impairment of the ubiquitinproteasome system by protein aggregation. Science. 2001;292(5521): $1552-1555$.

26. Ravikumar B, Duden R, Rubinsztein DC. Aggregate-prone proteins with polyglutamine and polyalanine expansions are degraded by autophagy. Hum Mol Genet. 2002;11(9):1107-1117.
27. Cha JH. Transcriptional dysregulation in Huntington's disease. Trends Neurosci. 2000;23(9):387-392.

28. Cepeda C, Hurst RS, Calvert CR, et al. Transient and progressive electrophysiological alterations in the corticostriatal pathway in a mouse model of Huntington's disease. J Neurosci. 2003;23(3): 961-969.

29. Ludolph AC, He F, Spencer PS, Hammerstad J, Sabri M. 3-Nitropropionic acid-exogenous animal neurotoxin and possible human striatal toxin. Can J Neurol Sci. 1991;18(4):492-498.

30. Gunawardena S, Goldstein LS. Polyglutamine diseases and transport problems: deadly traffic jams on neuronal highways. Arch Neurol. 2005; 62(1):46-51.

31. Browne SE, Beal MF. The energetics of Huntington's disease. Neurochem Res. 2004;29(3):531-546.

32. Harper PS. The epidemiology of Huntington's disease. Hum Genet. 1992;89(4):365-376.

33. Morrison PJ, Johnston WP, Nevin NC. The epidemiology of Huntington's disease in Northern Ireland. J Med Genet. 1995;32(7):524-530.

34. Peterlin B, Kobal J, Teran N, et al. Epidemiology of Huntington's disease in Slovenia. Acta Neurol Scand. 2009;119(6):371-375.

35. Alonso ME, Ochoa A, Boll MC, et al. Clinical and genetic characteristics of Mexican Huntington's disease patients. Mov Disord. 2009;24(13):2012-2015.

36. Simpson SA, Johnston AW. The prevalence and patterns of care of Huntington's chorea in Grampian. Br J Psychiatry. 1989;155:799-804.

37. Penney JB Jr, Young AB, Shoulson I, et al. Huntington's disease in Venezuela: 7 years of follow-up on symptomatic and asymptomatic individuals. Mov Disord. 1990;5(2):93-99.

38. Harper PS. The epidemiology of Huntington's disease. In: Bates G, Harper P, Jones L, editors. Huntington's disease. 3rd ed. Oxford Monographs on Medical Genetics: 2002.

39. Ribai P, Nguyen K, Hahn-Barma V, et al. Psychiatric and cognitive difficulties as indicators of juvenile huntington disease onset in 29 patients. Arch Neurol. 2007;64(6):813-819.

40. Biglan KM, Ross CA, Langbehn DR, et al. PREDICT-HD Investigators of the Huntington Study Group. Motor abnormalities in premanifest persons with Huntington's disease: the PREDICT-HD study. Mov Disord. 2009;24(12):1763-1772.

41. Tabrizi SJ, Langbehn DR, Leavitt BR, et al. TRACK-HD investigators Biological and clinical manifestations of Huntington's disease in the longitudinal TRACK-HD study: cross-sectional analysis of baseline data. Lancet Neurol. 2009;8(9):791-801.

42. Huntington Study Group PHAROS Investigators (Shoulson I, primary author). At risk for Huntington's disease: The PHAROS (Prospective Huntington At Risk Observational Study) cohort enrolled. Arch Neurol. 2006;63(7):991-996.

43. Huntington Study Group. Cooperative Huntington's Observational Research Trial [ClinicalTrials.gov identifier NCT00313495]. US National Institutes of Health. Available from: http://www.clinicaltrials. gov. Accessed May 3, 2010.

44. Solomon AC, Stout JC, Johnson SA, et al. Predict-HD Investigators of the Huntington Study Group. Verbal episodic memory declines prior to diagnosis in Huntington's disease. Neuropsychologia. 2007;45(8):1767-1776.

45. Johnson SA, Stout JC, Solomon AC, et al. Predict-HD Investigators of the Huntington Study Group. Beyond disgust: impaired recognition of negative emotions prior to diagnosis in Huntington's disease. Brain. 2007;130(Pt 7):1732-1744.

46. Paulsen JS, Langbehn DR, Stout JC, et al. Predict-HD Investigators and Coordinators of the Huntington Study Group. Detection of Huntington's disease decades before diagnosis: the Predict-HD study. J Neurol Neurosurg Psychiatry. 2008;79(8):874-880.

47. Duff K, Paulsen JS, Beglinger LJ, et al. Predict-HD Investigators of the Huntington Study Group. Psychiatric symptoms in Huntington's disease before diagnosis: the predict-HD study. Biol Psychiatry. 2007; 62(12):1341-1346.

48. Huntington Study Group. Unified Huntington's Disease Rating Scale: reliability and consistency. Mov Disord. 1996;11(2):136-142. 
49. The American College of Medical Genetics/American Society of Human Genetics Huntington Disease Genetic Testing Working Group. ACMG/ASHG statement. Laboratory guidelines for Huntington disease genetic testing. Am J Hum Genet. 1998;62(5): $1243-1247$.

50. Andrich J, Arning L, Wieczorek S, Kraus PH, Gold R, Saft C. Huntington's disease as caused by $34 \mathrm{CAG}$ repeats. Mov Disord. 2008;23(6):879-881.

51. Kenney C, Powell S, Jankovic J. Autopsy-proven Huntington's disease with 29 trinucleotide repeats. Mov Disord. 2007;22(1):127-130.

52. Snell RG, MacMillan JC, Cheadle JP, et al. Relationship between trinucleotide repeat expansion and phenotypic variation in Huntington's disease. Nat Genet. 1993;4(4):393-397.

53. Di ML, Squitieri F, Napolitano G, Campanella G, Trofatter JA, Conneally PM. Suicide risk in Huntington's disease. J Med Genet. 1993; 30(4):293-295.

54. Pollard J. Hurry Up and Wait: a cognitive care companion. 9/25/08, 142 pages. Lulu press.

55. Adam OR, Jankovic J. Symptomatic treatment of Huntington disease. Neurotherapeutics. 2008;5(2):181-197.

56. Phillips W, Shannon KM, Barker RA. The current clinical management of Huntington's disease. Mov Disord. 2008;23(11):1491-1504.

57. Roze E, Saudou F, Caboche J. Pathophysiology of Huntington's disease: from huntingtin functions to potential treatments. Curr Opin Neurol. 2008;21(4):497-503.

58. Imarisio S, Carmichael J, Korolchuk V, et al. Huntington's disease: from pathology and genetics to potential therapies. Biochem J. 2008; 412:191-209.

59. Walker FO. Huntington's disease. Lancet. 2007;369(9557):218-228.

60. Jankovic J. Treatment of hyperkinetic movement disorders. Lancet Neurol. 2009;8(9):844-856.

61. Bonelli RM, Wenning GK. Pharmacological management of Huntington's disease: an evidence-based review. Curr Pharm Des. 2006;12(21):2701-2720.

62. Mestre T, Ferreira J, Coelho MM, Rosa M, Sampaio C. Therapeutic interventions for symptomatic treatment in Huntington's disease. Cochrane Database Sys Rev. 2009;(3):CD006456.

63. Nakamura K, Aminoff MJ. Huntington's disease: clinical characteristics, pathogenesis and therapies. Drugs Today (Barc). 2007;43(2): 97-116.

64. Handley OJ, Naji JJ, Dunnett SB, Rosser AE. Pharmaceutical, cellular and genetic therapies for Huntington's disease. Clin Sci (Lond). 2006; 110(1):73-88.

65. Bonelli RM, Hofmann P. A review of the treatment options for Huntington's disease. Expert Opin Pharmacother. 2004;5(4):767-776.

66. Grimbergen YA, Roos RA. Therapeutic options for Huntington's disease. Curr Opin Investig Drugs. 2003;4(1):51-54.

67. Frank SA, Jankovic J. Advances in the pharmacological management of Huntington's Disease. Drugs. 2010;70(5):561-571.

68. Paleacu D. Tetrabenazine in the treatment of Huntington's Disease. Neuropsychiatr Dis Treat. 2007;3(5):545-551.

69. Bagchi SP. Differential interactions of phencyclidine with tetrabenazine and reserpine affecting intraneuronal dopamine. Biochem Pharmacol. 1983;32(19):2851-2856.

70. Pettibone DJ, Pflueger AB, Totaro JA. Tetrabenazine-induced depletion of brain monoamines: mechanism by which desmethylimipramine protects cortical norepinephrine. Eur J Pharmacol. 1984; 102(3-4):431-436.

71. Mehvar R, Jamali F. Concentration-effect relationships of tetrabenazine and dihydrotetrabenazine in the rat. J Pharm Sci. 1987;76(6): 461-465.

72. Thibaut F, Faucheux BA, Marquez J, et al. Regional distribution of monoamine vesicular uptake sites in the mesencephalon of control subjects and patients with Parkinson's disease: a postmortem study using tritiated tetrabenazine. Brain Res. 1995;692(1-2): 233-243.
73. Kenney C, Hunter C, Davidson A, Jankovic J. Short-term effects of tetrabenazine on chorea associated with Huntington's disease. Mov Disord. 2007;22(1):10-13.

74. Scherman D, Henry JP. Reserpine binding to bovine chromaffin granule membranes. Characterization and comparison with dihydrotetrabenazine binding. Mol Pharmacol. 1984;25(1):113-122.

75. Mehvar R, Jamali F, Watson MW, Skelton D. Pharmacokinetics of tetrabenazine and its major metabolite in man and rat. Bioavailability and dose dependency studies. Drug Metab Dispos. 1987;15(2): 250-255.

76. Roberts MS, Watson HM, McLean S, Millingen KS. Determination of therapeutic plasma concentrations of tetrabenazine and an active metabolite by high-performance liquid chromatography. J Chromatogr. 1981;226(1):175-182.

77. Roberts MS, McLean S, Millingen KS, Galloway HM. The pharmacokinetics of tetrabenazine and its hydroxy metabolite in patients treated for involuntary movement disorders. Eur J Clin Pharmacol. 1986;29(6):703-708.

78. Huntington Study Group. Tetrabenazine as antichorea therapy in Huntington disease: a randomized controlled trial. Neurology. 2006; 66(3):366-372.

79. Jankovic J, Beach J. Long-term effects of tetrabenazine in hyperkinetic movement disorders. Neurology. 1997;48(2):358-362.

80. Kenney C, Hunter C, Jankovic J. Long-term tolerability of tetrabenazine in the treatment of hyperkinetic movement disorders. Mov Disord. 2007; 22(2):193-197.

81. Fasano A, Cadeddu F, Guidubaldi A, et al. The long-term effect of tetrabenazine in the management of Huntington disease. Clin Neuropharmacol. 2008;31(6):313-318.

82. Frank S. Tetrabenazine as anti-chorea therapy in Huntington disease: an open-label continuation study. Huntington Study Group/TETRA-HD Investigators. BMC Neurol. 2009;9:62.

83. Frank S, Ondo W, Fahn S, et al. A study of chorea after tetrabenazine withdrawal in patients with Huntington's disease. Clin Neuropharmacol. 2008;31(3): 127-133.

84. Quinn N, Marsden CD. A double blind trial of sulpiride in Huntington's disease and tardive dyskinesia. J Neurol Neurosurg Psychiatry. 1984; 47(8):844-847.

85. Deroover J, Baro F, Bourguignon RP, Smets P. Tiapride versus placebo: a double-blind comparative study in the management of Huntington's chorea. Curr Med Res Opin. 1984;9(5):329-338.

86. Leonard DP, Kidson MA, Brown JG, Shannon PJ, Taryan S. A double blind trial of lithium carbonate and haloperidol in Huntington's chorea. Aust N Z J Psychiatry. 1975;9(2):115-118.

87. Barr AN, Fischer JH, Koller WC, Spunt AL, Singhal A. Serum haloperidol concentration and choreiform movements in Huntington's disease. Neurology. 1988;38(1):84-88.

88. Bonelli RM, Mahnert FA, Niederwieser G. Olanzapine for Huntington's disease: an open label study. Clin Neuropharmacol. 2002;25(5): 263-265.

89. Bonelli RM, Niederwieser G, Tribl GG, Költringer P. High-dose olanzapine in Huntington's disease. Int Clin Psychopharmacol. 2002; 17(2):91-93.

90. Paleacu D, Anca M, Giladi N. Olanzapine in Huntington's disease. Acta Neurol Scand. 2002;105(6):441-444.

91. Squitieri F, Cannella M, Piorcellini A, Brusa L, Simonelli M, Ruggieri S. Short-term effects of olanzapine in Huntington disease. Neuropsychiatry Neuropsychol Behav Neurol. 2001;14(1):69-72.

92. Dipple HC. The use of olanzapine for movement disorder in Huntington's disease: a first case report. J Neurol Neurosurg Psychiatry. 1999;67(1):123-124.

93. Cankurtaran ES, Ozalp E, Soygur H, Cakir A. Clinical experience with risperidone and memantine in the treatment of Huntington's disease. J Natl Med Assoc. 2006;98(8):1353-1355.

94. Erdemoglu AK, Boratav C. Risperidone in chorea and psychosis of Huntington's disease. Eur J Neurol. 2002;9(2):182-183. 
95. Madhusoodanan S, Brenner R. Use of risperidone in psychosis associated with Huntington's disease. Am J Geriatr Psychiatry. 1998;6(4): 347-349.

96. Parsa MA, Szigethy E, Voci JM, Meltzer HY. Risperidone in treatment of choreoathetosis of Huntington's disease. J Clin Psychopharmacol. 1997; 17(2):134-135.

97. Alpay M, Koroshetz WJ. Quetiapine in the treatment of behavioral disturbances in patients with Huntington's disease. Psychosomatics. 2006;47(1):70-72.

98. Seitz DP, Millson RC. Quetiapine in the management of psychosis secondary to Huntington's disease: a case report. Can J Psychiatry. 2004;49(6):413.

99. Bonelli RM, Niederwieser G. Quetiapine in Huntington's disease: a first case report. J Neurol. 2002;249(8):1114-1115.

100. van Vugt JP, Siesling S, Vergeer M, van der Velde EA, Roos RA. Clozapine versus placebo in Huntington's disease: a double blind randomised comparative study. J Neurol Neurosurg Psychiatry. 1997; 63(1):35-39.

101. Ciammola A, Sassone J, Colciago C, et al. Aripiprazole in the treatment of Huntington's disease: a case series. Neuropsychiatr Dis Treat. 2009;5:1-4.

102. Brusa L, Orlacchio A, Moschella V, Iani C, Bernardi G, Mercuri NB Treatment of the symptoms of Huntington's disease: preliminary results comparing aripiprazole and tetrabenazine. Mov Disord 2009;24(1):126-129.

103. Lin WC, Chou YH. Aripiprazole effects on psychosis and chorea in a patient with Huntington's disease. Am J Psychiatry. 2008;165(9): 1207-1208.

104. Lucetti C, Gambaccini G, Bernardini S, et al. Amantadine in Huntington's disease: open-label video-blinded study. Neurol Sci. 2002;23 Suppl 2:S83-S84.

105. Stewart JT. Adverse behavioral effects of amantadine therapy in Huntington's disease. South Med J. 1987;80(10):1324-1325.
106. Huntington Study Group. Dosage effects of riluzole in Huntington's disease: a multicenter placebo-controlled study. Neurology. 2003; 61(11):1551-1556.

107. Landwehrmeyer GB, Dubois B, de Yebenes JG, et al. Riluzole in Huntington's disease: a 3-year, randomized controlled study. Ann Neurol. 2007;62(3):262-272.

108. Peiris JB, Boralessa H, Lionel ND. Clonazepam in the treatment of choreiform activity. Med J Aust. 1976;1(8):225-227.

109. Frattola L, Albizzati MG, Alemani A, Bassi S, Ferrarese C, Trabucchi M. Acute treatment of Huntington's chorea with lisuride. J Neurol Sci. 1983;59(2):247-253.

110. Vitale C, Marconi S, Di ML, et al. Short-term continuous infusion of apomorphine hydrochloride for treatment of Huntington's chorea: a double blind, randomized cross-over trial. Mov Disord. 2007; 22(16):2359-2364.

111. Corsini GU, Onali P, Masala C, Cianchetti C, Mangoni A, Gessa G. Apomorphine hydrochloride-induced improvement in Huntington's chorea: stimulation of dopamine receptor. Arch Neurol. 1978; 35(1):27-30.

112. Low PA, Allsop JL, Halmagyi GM. Huntington's chorea: the rigid form (Westphal variant) treated with levodopa. Med J Aust. 1974;1(11): 393-394.

113. Low PA, Allsop JL. Huntington's chorea - the rigid form (Westphal variant) treated with 1-DOPA: a case report. Proc Aust Assoc Neurol. 1973;10(0):45-46.

114. Magnet MK, Bonelli RM, Kapfhammer HP. Amantadine in the akinetic-rigid variant of Huntington's disease. Ann Pharmacother. 2004;38(7-8):1194-1196.

115. Bonelli RM, Niederwieser G, Diez J, Gruber A, Költringer P. Pramipexole ameliorates neurologic and psychiatric symptoms in a Westphal variant of Huntington's disease. Clin Neuropharmacol. 2002;25(1):58-60.

116. http://www.xenazineusa.com. Accessed 3 May 2010.
Neuropsychiatric Disease and Treatment

\section{Publish your work in this journal}

Neuropsychiatric Disease and Treatment is an international, peerreviewed journal of clinical therapeutics and pharmacology focusing on concise rapid reporting of clinical or pre-clinical studies on a range of neuropsychiatric and neurological disorders. This journal is indexed on PubMed Central, the 'PsycINFO' database and CAS, and is the official

\section{Dovepress}

journal of The International Neuropsychiatric Association (INA). The manuscript management system is completely online and includes a very quick and fair peer-review system, which is all easy to use. Visit http://www.dovepress.com/testimonials.php to read real quotes from published authors. 